$$
\text { "Hohenwarter" — 2009/2/18 — 23:27 — page } 311 \text { — \#1 }
$$

\title{
Design guidelines for dynamic mathematics worksheets
}

\author{
Markus Hohenwarter and Judith Preiner
}

\begin{abstract}
In a Math and Science Partnership project in Florida, middle school teachers are using the dynamic mathematics software GeoGebra to create interactive online worksheets for mathematics learning. Formative evaluation of these materials based on design principles of multimedia learning has lead to a list of specific design guidelines for such dynamic worksheets that we present in this article. These design guidelines can give advice both for the creation of new dynamic worksheets and the evaluation of existing material on the Internet.
\end{abstract}

Key words and phrases: design principles, multimedia learning, dynamic mathematics software, interactive online material, GeoGebra.

ZDM Subject Classification: C30, U59, U79.

\section{Introduction}

In this article we describe guidelines for the design of dynamic mathematics worksheets based on formative evaluation of materials created by middle school teachers in Florida.

First, we introduce the Math and Science Partnership project at Florida Atlantic University and describe the software tools used by the participating teachers to create interactive teaching materials. Then we present our theoretical framework, the design principles of multimedia learning by Clark and Mayer [2], that we used to evaluate the created materials. Next we discuss related considerations in the user interface design of the used software system GeoGebra [4] developed

Copyright (C) 2008 by University of Debrecen 
by one of the authors. Finally, we present our design guidelines for interactive online worksheets with regard to the design principles of multimedia learning.

\subsection{Math and Science Partnership}

Based on ten years of prior teacher enhancement projects, the Math and Science Partnership (MSP) project between the Department of Mathematical Sciences at Florida Atlantic University (FAU) and the School Board of Broward County (SBBC) started in August 2004 funded by a grant from the US National Science Foundation (NSF).

The principal investigators Dr. Heinz-Otto Peitgen and Dr. Richard F. Voss of this five year program called Standards Mapped Graduate Education and Mentoring designed a special curriculum that consists of advanced mathematics content as well as best practice examples for the use of technology in teaching mathematics. Goal of this curriculum is to meet the needs of middle school mathematics teachers and to provide mathematical and technological content connected to their everyday teaching situation in classrooms. Through evening classes, annual summer institutes, as well as biannual pedagogy conferences the participating in-service teachers are able to earn a Master's degree in Science and Teaching at FAU. The three major goals of this project are:

- Increase of mathematical and pedagogical content knowledge

- Effective use of technology for learning and teaching mathematics

- Impact on university as well as school district level, and students' performance

In this article, we focus on the second goal of the project concerning the effective use of technology. In August 2006 and May 2007, two supplemental grants were approved by NSF, allowing an intensified integration of the dynamic mathematics software GeoGebra into the project. This reinforces the technology component of the project in several ways:

Best practice examples: Experienced teachers present best practice examples of their use of GeoGebra and other technology in their classrooms and discuss their experiences with other teachers. Thereby, the selective use of technology is reinforced in order to foster an effective use of technology in the classroom.

Multiple representations: GeoGebra provides both an algebra and a graphics window to represent mathematical objects. This supports the use of multiple representations in course journals and materials created by the participating teachers. 
Discovery learning: Teachers create their own interactive instructional materials using appropriate software in order to foster discovery learning [1], [8] in their classrooms.

Collaboration: Teachers in our project form a professional community that is connected to teachers from all around the world using collaborative software like wikis and forums on the Internet.

\subsection{Creating interactive teaching materials}

In Fall 2006, a first group of ten teachers took a special evening class with Markus Hohenwarter focused on the use of GeoGebra for teaching and learning mathematics. Part of their assignments was to create web based interactive teaching materials using GeoGebra in order to enhance their students' learning and understanding of mathematical concepts. Those materials were formatively evaluated throughout the semester by the instructor and in plenary discussions in order to both improve their quality and to gather information about major difficulties and problems.

Based on these experiences a special sequence of technology workshops was developed for the Spring semester 2007 in order to prepare about 30 more teachers for the creation of so called 'Multimedia Lessons' for their own teaching. Using software for dynamic mathematics (GeoGebra [9]), spreadsheet (MS Excel), text processing (MS Word), presentations (MS PowerPoint), interactive exercises (HotPotatoes [11]), and web page editing (NVU [10]), they were asked to develop lesson plans with corresponding instructional materials for their students and try them out in their classrooms.

Again, their materials were formatively evaluated and discussed throughout the semester. Interestingly, the most common problems found with the materials of the middle school teachers were not related to technological difficulties that occurred during the creation process of their dynamic worksheets. Most help was needed concerning design issues like layout of the worksheet, conception of the dynamic figure, and phrasing of questions and explanations.

\section{Theoretical framework}

For the formative evaluation of the instructional materials created by teachers in our MSP classes we relied on the multimedia design principles by Clark and Mayer [2] which are based on empirical research and cognitive learning theory. 
"Hohenwarter" — 2009/2/18 — 23:27 — page 314 — \#4

Two key statements of cognitive learning theory are that human memory has limited capacity for processing information and that learning occurs by active processing in the memory system [2, p. 35].

Therefore, instructional methods that overload working memory make learning more difficult. The burden imposed on working memory in form of information that must be held plus information that must be processed is referred to as cognitive load. Methods that reduce cognitive load foster learning by freeing working memory capacity for the rehearsal and integration processes [2, p. 38].

Thus, the cognitive load in instructional materials should be small in order to foster more effective learning of mathematical concepts. The following design principles for multimedia learning give concrete information on how cognitive load can be reduced.

\subsection{Design principles for multimedia learning}

Out of the original seven design principles stated by Clark and Mayer, we focus on those four which we found most appropriate for GeoGebra's dynamic worksheets. We did not consider the Modality Principle and Redundancy Principle which are both related to the use of audio narration as well as the Learner Control Principle which is more important for learning units than for single worksheets.

Multimedia Principle: Use words and graphics rather than words alone [2, p. 51]. Several empirical studies showed that the combination of text and graphics fosters successful learning more than the use of text without graphics [2, p. 61]. Moreno and Mayer [6] used a mathematical computer game in order to teach students addition and subtraction of integers. While the control group was taught using a text based drill and practice program, the treatment group was provided with a graphical representation of the number line on which a rabbit was moving to the right or left corresponding to the positive and negative numbers involved in the tasks. This study showed that the success of learning was considerably better in the treatment group than in the control group.

Figure 1 shows a screen shot of a dynamic GeoGebra construction to visualize integer addition. The two integers $a$ and $b$ are changeable using 


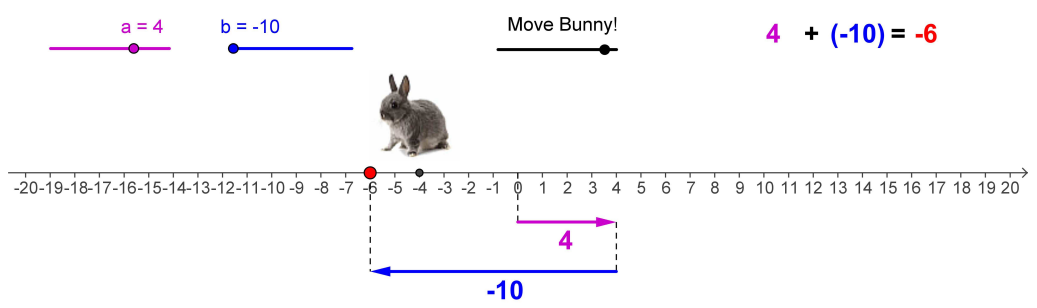

Figure 1. Integer adding in GeoGebra

sliders. This changes both the arrows below the number line and the equation at the upper right dynamically. Using the Move Bunny! slider in the displayed example, the rabbit moves four units facing right, turns, and then moves ten units facing left.

Contiguity Principle: Place corresponding words and graphics near each other [2, p. 67]. Sweller [7] used two differently designed versions of the same geometry problem in a study. In version 1 the solution of an example problem was integrated in the figure (integrated text), while in the 'traditional' version 2 this text was displayed below the figure (separated text). The group using version 1 performed better in a post-test with similar problems than the group which used the traditional version.

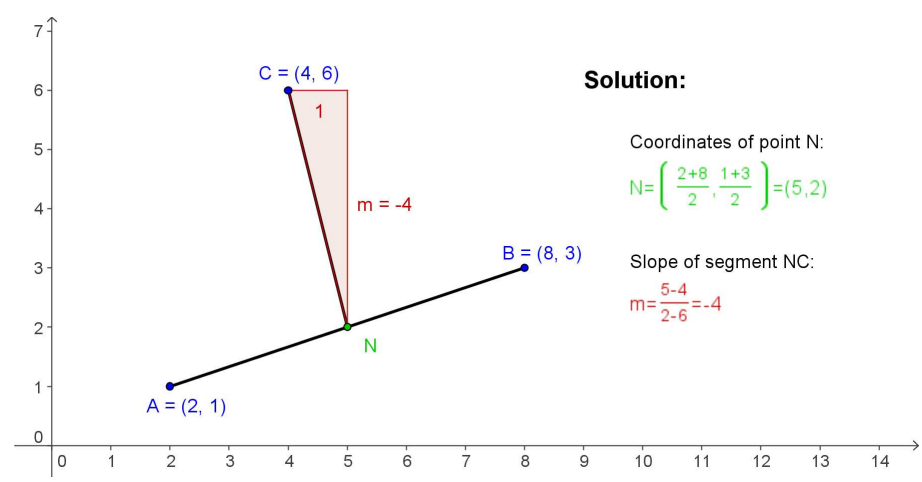

Figure 2. Sweller's geometry example recreated with GeoGebra

Figure 2 shows a GeoGebra construction of the geometry example mentioned above. Given points $A=(2,1)$ and $B=(8,3)$ and the midpoint $N$ 
of segment $\overline{A B}$. In order to find the slope of segment $\overline{N C}$ where $C=(4,6)$ we need to calculate the coordinates of point $N$ before we are able to find slope $m$ of segment $\overline{N C}$. In the displayed figure, the explaining text is integrated into the figure to address the Contiguity Principle. In GeoGebra this construction can be modified by dragging points with the mouse which dynamically changes the text of the solution. Additionally, the colors used in the text matches the colors of corresponding objects to make it easier for students to grasp this connection.

Coherence Principle: Adding interesting material can hurt learning [2, p. 111]. Already in 1913, Dewey [3] had doubts whether adding interesting materials to boring content would foster learning.

When things have to be made interesting, it is because interest itself is wanting. Moreover, the phrase is a misnomer. The thing, the object is no more interesting than it was before [3].

Such 'interesting materials' can be categorized as follows.

1. Entertaining stories related but not essential to the instructional objective

2. Background music and sound added for motivation

3. Detailed textual descriptions [2, p. 111]

This kind of materials can lead to distraction, disruption, or seduction $[2$, p. 111] and thus harm the learning process because they increase the cognitive load. Therefore, they should be excluded from instructional materials.

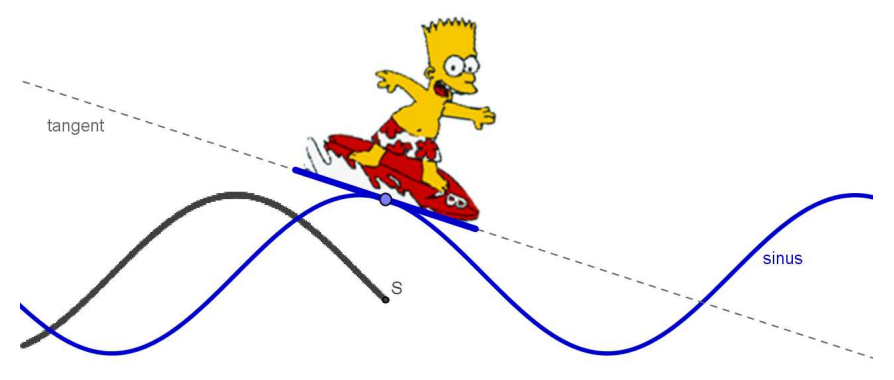

Figure 3. GeoGebra example for Coherence Principle

Figure 3 shows the screen shot of a dynamic GeoGebra construction that contains a sine function with its tangent through a moveable point. 
Point $S$ represents the slope value depending on the position of the point on the sine function and leaves a trace that shows the corresponding slope function. Although the surfer attached to the moveable tangent line may seem motivating for students, this picture is distracting from the instructional objective, i.e. the concept of slope. Thus, it should be removed in this situation.

Personalization Principle: Use conversational style [...] [2, p. 131]. In conversational style the reader is addressed directly using the word 'you' and is treated like a dialog partner. Different studies show that students who learned with text written in conversational style performed better on transfer-tests than students who learned from more formal text [6]. Conversational style is easier to understand because it is closer to everyday's language. Directly addressing the readers also increases their motivation to put effort into working on a given task or problem. The table below shows an example for the same task presented in formal and conversational style.

\begin{tabular}{|c|c|}
\hline Formal Style & Conversational Style \\
\hline $\begin{array}{l}\text { Dragging one of the triangle's ver- } \\
\text { tices affects the position of its ortho- } \\
\text { center. In which situation does the } \\
\text { orthocenter lie outside the triangle? }\end{array}$ & $\begin{array}{l}\text { Drag any vertex of the triangle to } \\
\text { change the position of its orthocen- } \\
\text { ter. Can you move the orthocenter } \\
\text { to a positioin outside of the triangle? } \\
\text { Describe the special type of triangle } \\
\text { for which this situation applies. }\end{array}$ \\
\hline
\end{tabular}

\subsection{GeoGebra's user interface}

Before we consider the consequences of the design principles of multimedia learning for dynamic worksheets created with GeoGebra, let us have a quick look at the software's application user interface first.

The Multimedia Principle is respected in several ways in GeoGebra. On the one hand, the software offers two views with connected algebraic (i.e. textual) and graphical representations of the same mathematical objects. On the other hand, interactive dynamic figures can be combined with static or dynamic text in the graphics view too.

The Contiguity Principle is addressed by pop up text that show the definition of an object when you move the mouse over it. Furthermore, labels can consist 
of either the name of an object, or its value, or both of them. The algebraic and graphical representation of an object are always displayed in the same color to facilitate finding corresponding representations in the algebra window, graphics window, and also construction protocol. Furthermore, static and dynamic text can easily be inserted into the graphics window and placed near corresponding objects.

The Coherence Principle is followed by keeping the user interface free from distractions like glaring colors or unnecessary decorations.

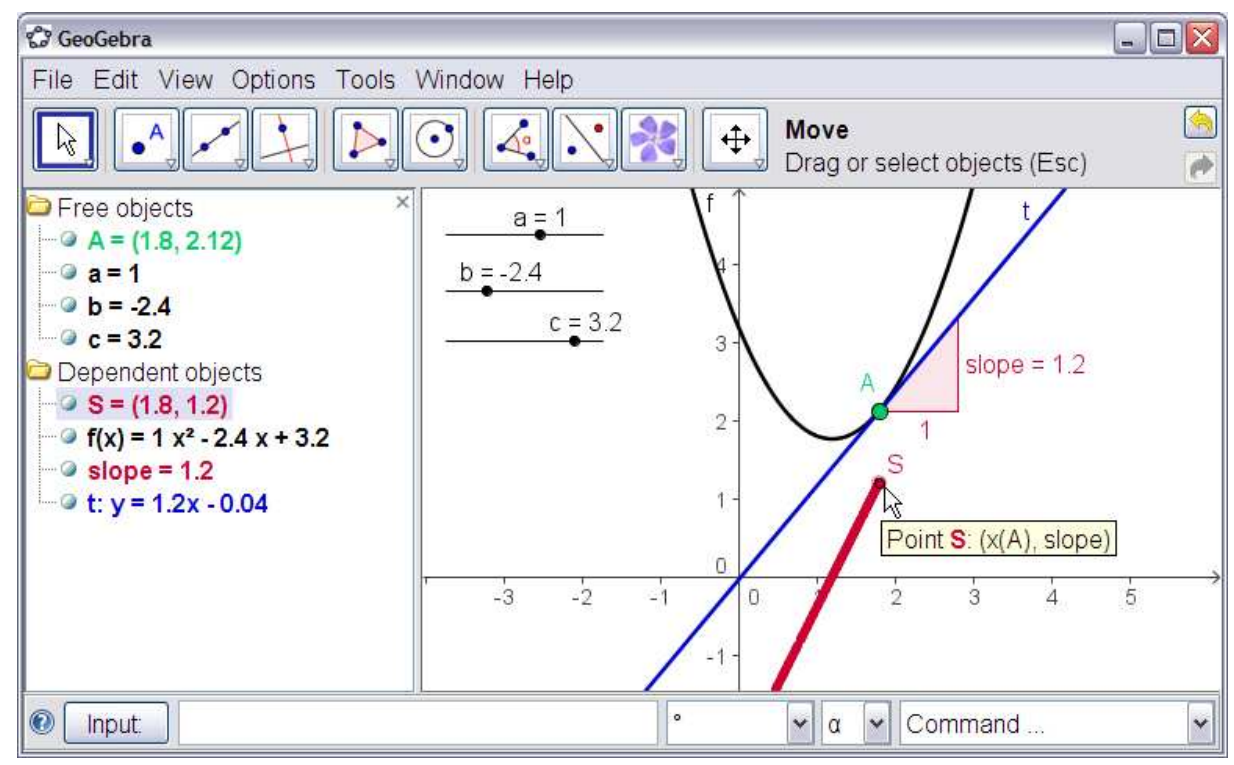

Figure 4. User interface of GeoGebra

\section{Design guidelines for dynamic worksheets}

All GeoGebra constructions can be exported into so called Dynamic Worksheets which are interactive online materials [5]. A dynamic worksheet (html page) consists of a dynamic figure (applet) and text with explanations and/or tasks. Such materials can be used for presentation purposes, but their main purpose is to provide learning environment for students where they can actively perform guided mathematical experiments. 
The following design guidelines are the result of a formative evaluation of dynamic worksheets created by teachers in our MSP classes during Fall 2006 and Spring 2007. The guidlines are based on the design principles for multimedia learning discussed above. We have summarized these guidelines to address and avoid common mistakes during the creation process of dynamic worksheets as well as to increase their quality with the hope that they will foster more effective learning.

Although some of these guidelines may seem obvious, we have found it very important in our work with teachers to discuss and explain them in detail.

\subsection{Layout of dynamic worksheets}

Avoid scrolling: Your entire worksheet should fit on one screen. Students should not have to scroll between the tasks and the interactive figure (see Contiguity Principle). We consider $1024 \times 768$ or $1280 \times 1024$ pixels as today's usual screen size which constrains the size of the dynamic worksheet. Using an HTML editor like NVU you can use tables to arrange text, images, and interactive figures so they fit on one screen. If this is not possible, consider breaking the dynamic worksheet into several pages.

Short explanation: At the beginning of a dynamic worksheet, you should give an explanation of its content. Keep the text short (no more than one or two sentences) and write it in a personal style (see Personalization Principle).

Few tasks: You will usually add questions or tasks to make sure that your students use the worksheet actively. Place these tasks close to the interactive applet (e.g. directly below it). Don't use more than three or four questions / tasks to avoid scrolling (see Contiguity Principle). If you have more tasks, consider breaking your worksheet into several pages.

Avoid distractions: Make sure that your dynamic worksheet just contains objects that are relevant for the objectives. Neither use unnecessary background or purely decorative images, nor background music on the web page (see $\mathrm{Co}$ herence Principle) in order not to distract your students from reaching the objectives.

Figure 5 shows an entire dynamic worksheet created with GeoGebra that allows students to explore properties of the orthocenter of a triangle. By modifying the dynamic construction students can examine the orthocenter of a great variety of different triangles and therefore better understand the mathematical concept instead of just one special case. Several key words within the explanation and 
"Hohenwarter" — 2009/2/18 — 23:27 — page 320 — \#10

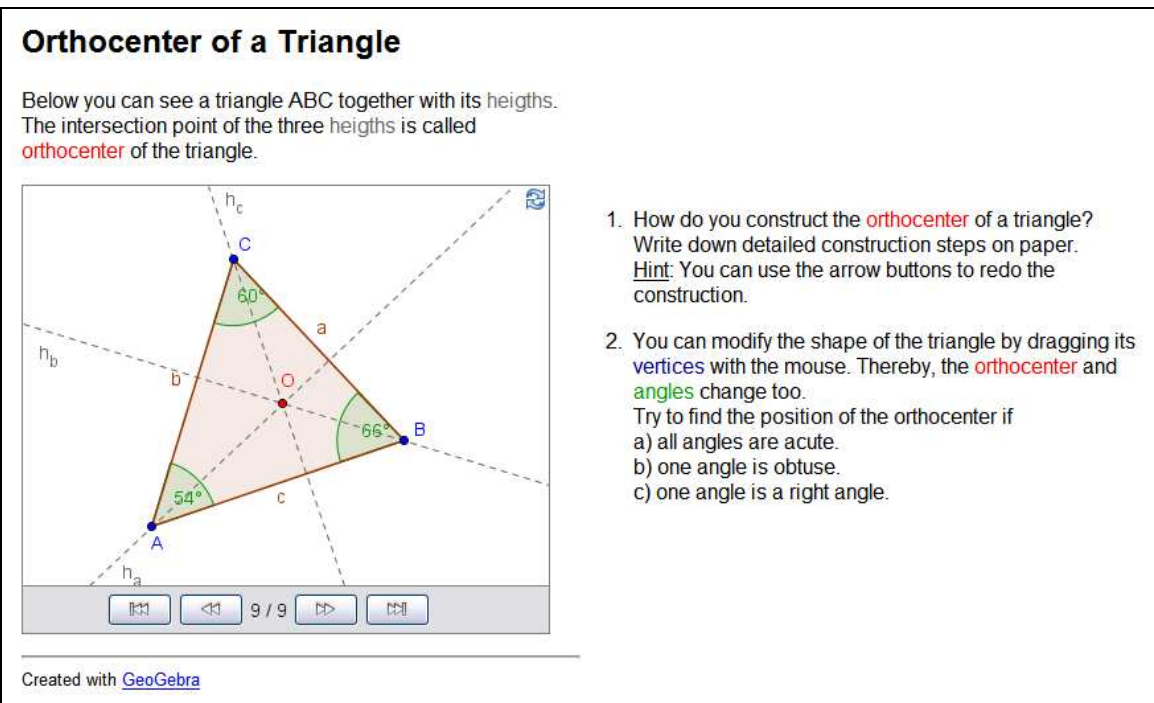

Figure 5. Dynamic worksheet example

tasks match the color of the corresponding objects in order to facilitate finding them within the construction. Furthermore, the tasks are placed next to the dynamic construction in order to fit all information on one screen and avoid additional cognitive load through scrolling (see Multimedia Principle and Contiguity Principle).

\subsection{Dynamic figures}

Interactivity: Allow as much interactivity as possible in your dynamic figure. As a rule of thumb, all visible objects should be movable or changeable in some way (see Coherence Principle). Your dynamic figure should provide plenty of freedom to explore the relations of its mathematical objects and discover mathematical concepts.

Easy-to-use: Try to make your dynamic figure as easy to use as possible. If an object can be moved or changed, try to make this obvious, e.g. all movable points could be red or larger in size. If you don't want objects to be changed, fix them (e.g. text, functions or slider positions) so they cannot be moved accidentally (see Coherence Principle). 


$$
\text { "Hohenwarter" — 2009/2/18 — 23:27 — page 321 — \#11 }
$$

Size matters: Your dynamic figure should be large enough to allow all intended manipulations, but small enough to fit on one screen and still leave sufficient space for explanations and questions on the surrounding web page (see Contiguity Principle).

Use dynamic text: Dynamic text, like the length of a changeable segment, should be placed close to the corresponding object in your applet (see Contiguity Principle).

Avoid static text: Too much text can easily clutter your interactive applet. Instead, place static text like explanations or questions on the web page that includes your dynamic figure (see Multimedia Principle).

First appearance: When a dynamic worksheet is opened you should be able to read all labels and important information (see Coherence Principle). For example, a point label should not be crossed by a line.

\subsection{Explanations and tasks}

Short, clear and personal style: Try to write your explanations and questions in a short, clear and conversational style (see Personalization Principle). Use the term 'you' within the text and try to address the students directly.

Small number of questions: Limit your number of questions or tasks per worksheet to three or four to avoid scrolling (see Coherence Principle). If you want to ask more questions, create a new worksheet (see subsection 3.1).

Use specific questions: Avoid general questions like 'What is always true about X?' and make clear what the students should do, e.g. 'What happens to $\mathrm{X}$ when you move Y?' (see 'guided discovery learning', [8]). We recommend that your students should take notes while they work with a dynamic worksheet. If you want them to write down their answers on paper, say so on the worksheet.

Refer to your applet: Your text should support the use of your interactive applet. For example, try to explain a new term by referring to your applet instead of using an isolated textual definition (see Multimedia Principle). Additionally, you can color certain keywords to match the formatting style of the object they refer to. This makes the text easier to read and helps your students to find corresponding representations of the same object (see Contiguity Principle). 
"Hohenwarter" — 2009/2/18 — 23:27 — page 322 — \#12

Your audience are learners: If you want to provide information for other educators (e.g. lesson plan, solutions), do so in a separate document (e.g. web page, pdf-document). Your students should not be distracted or confused by such information (see Coherence Principle).

Demonstration figure: If your interactive figure is meant for presentation only it might be better to have no tasks or questions on the web page (see Coherence Principle). If you include text, it should be understandable for students as well (see Personalization Principle).

\section{Conclusion}

Our design guidelines for dynamic worksheets are intended to be helpful for educators during the design process and evaluation of interactive online materials, especially but not only based on dynamic mathematics software like GeoGebra. The guidelines are derived from recognized design principles of multimedia learning and have been found useful in our work with in-service teachers.

Right now these guidelines are based on experience and reasoned through research on multimedia learning. In order to transform them into quality criteria for dynamic worksheets, classroom research on the effects of different worksheet designs on student learning outcomes will be necessary.

\section{References}

[1] J. Bruner, The act of discovery, Harvard Educational Review, no. 31 (1961), 21-32.

[2] R. Clark and R. E. Mayer, e-Learning and the Science of Instruction, Pfeiffer, San Francisco, 2002.

[3] J. Dewey, Interest and effort in education, MA: Houghton Mifflin, Cambridge, 1913.

[4] M. Hohenwarter and J. Preiner, Dynamic mathematics with GeoGebra, Journal of Online Mathematics and its Applications, MAA, ID 14487 (2007).

[5] M. Hohenwarter and J. Preiner, Creating mathlets using open source tools, Journal of Online Mathematics and its Applications, MAA, ID 15747 (2007).

[6] R. Moreno and R. E. Mayer, Engaging students in active learning: The case for personlized multimedia messages, Journal of Educational Psychology 94 (2000), 156-163.

[7] J. Sweller and others, Cognitive load and selective attention as factors in the structuring of technical material, Journal of Experimental Psychology: General 119 (1990), 176-192. 
"Hohenwarter" — 2009/2/18 — 23:27 — page 323 — \#13

$\underline{\text { Design guidelines for dynamic mathematics worksheets }}$

[8] W. Van Joolingen, Cognitive tools for discovery learning, International Journal of Artificial Intelligence in Education 10 (1999), 385-397.

[9] GeoGebra, http://www.geogebra.org.

[10] NVU, http://www.nvu.com.

[11] HotPotatoes, http://hotpot.uvic.ca/.

MARKUS HOHENWARTER

MATHEMATICAL SCIENCES

FLORIDA ATLANTIC UNIVERSITY

BOCA RATON

USA

E-mail: mhohen@math.fau.edu

JUDITH PREINER

MATHEMATICAL SCIENCES

FLORIDA ATLANTIC UNIVERSITY

BOCA RATON

USA

E-mail: jpreiner@math.fau.edu

(Received September, 2007) 